analysis. Thanks are due to Patricia Zybert for her work on the diagrams.

The study was carried out with the assistance of funds from the National Institute of Health (Grants nos. 3-R01-HD-04454 and 5-R01-HD-06751) and the New York State Department of

Mental Hygiene. The writing of this paper was greatly facilitated by the award of a John Simon Guggenheim Fellowship for 1972-1973 to M. Susser.

12. Requests for reprints should be addressed to: Z. Stein, M.A., M.B., B.Ch., Columbia University School of Public Health, 600 W. 168 th St., New York, N. Y. 10032 (USA).

13. Accepted for publication September 6, 1974
Collager fibroblasts hydroxyproline
Iysine osteogenesis imperfecta proline

\title{
Dominantly Inherited Osteogenesis Imperfecta in Man: An Examination of Collagen Biosynthesis
}

\author{
GERALD LANCASTER, ${ }^{(35)}$ HY GOLDMAN, CHARLES R. SCRIVER, \\ REYNOLD J. M. GOLD, AND INES WONG \\ deBelle Labcratory for Biochemical Genetics, McGill University-Montreal Children's Hospital \\ Research Institute, Montreal, Quebec, Canada
}

\section{Extract}

We have examined control subjects and patients in an effort to discover a metabolic basis for dominantly inherited osteogenesis imperfecta (OI). Studies were carried out in vitro with cultured skin fibroblasts obtained from OI patients, and in vivo on peptide-bound hydroxyproline excretion in urine. Urinary hydroxyproline excretion (milligrams/24 hr) adjusted for age is essentially normal in OI patients, although the mean excretion rate is below average. The latter finding is presumably a reflection of the smaller body mass of OI patients.

The OI skin fibroblasts, matched for age of donor, site of biopsy, phase of growth, and generation number in culture, incorporate L-proline into hot trichloroacetic acid (TCA)-soluble protein (collagen) at normal rates. The rate of conversion of proline to hydroxyproline in the nascent polypeptide is also normal in OI. Incorporation of L-lysine was also normal in OI. These findings indicate that peptide synthesis of collagen is not impaired in OI.

Rates of galactose incorporation into collagen and the extractability of collagen into normal saline or $0.2 \mathrm{M}$ citric acid were all normal both in OI cells and in the culture medium recovered from the monolayer. These findings, in combination with the urinary data on hydroxyproline excretion in vivo reveal that cross-linking and export of collagen in OI is essentially normal.

The elution profile after ion exchange chromatography of fibroblast collagen on carboxymethyl (CM)-Sephadex was also examined. The normal $2 / 1$ ratio of peak 1 (largely $\alpha 1$ (I) chains) to peak 2 (largely $\alpha 2$ chains) was found in OI fibroblast extracts, which implies that synthesis and initial aggregation of the two types of polypeptide to yield $[\alpha 1(\mathrm{I})]_{2} \alpha 2$ collagen composition is not abnormal in OI.

Despite the negative biochemical findings, a consistent defect in the morphology of OI cells was identified in the log phase and the confluent phase of monolayer cultures. The finding is characterized by irregular packing of the aggregated cells and by an irregular tessellated appearance of the individual OI fibroblast. This observation reassures us that the inherited defect is expressed in vitro.

\section{Speculation}

An abnormality in the primary sequence of polypeptide chain in collagen would be compatible with all of our findings and with the genetics of OI. The mutant allele would affect only about half the products, under the control of only one of the loci determining the polypeptide sequences in collagen chains. Because the OI allele is not expressed in cartilage, a tissue without $\alpha 2$ collagen chains, the defect in OI wnיינה perhaps be found in the $\alpha 2$ polypeptide. However, since the $\alpha 1$ (II) chain of cartilage differs in amino acid composition and in hydroxylysine-linked carbohydrate from the $\alpha 1$ (I) chains of noncartilagenous structures, a defect in $\alpha 1$ (I) chains at the nonhomologous residues will also require investigation.

Osteogenesis imperfecta is a disease characterized by osteoporosis, multiple fractures, and dental involvement (7, 15). Blue sclerae, deafness, and slow healing of wounds are also present to variable extent. Cartilage involvement appears to be minimal or absent. The disease is most commonly inherited as an autosomal dominant with variable expression of phenotype, ranging from the severe congenita form, which is evident in utero and has been diagnosed antenatally (8), to the mild tarda form which generally improves with the onset of puberty.

The dominant mode of inheritance suggests that a structural protein is probably involved in the disease (16). Collagen 
which is present to a very large extent in the affected tissues, i.e., bone, teeth, and skin, is a likely candidate for the defect. Furthermore, a number of recent histologic studies, notably those of Eichholtz and Muller (4), Blumcke and Niedorf (1), and the work of Falvo and Bullough (5) all point to a defect in this species of protein.

The studies reported here describe normal biosynthesis, maturation, and excretion of collagen in cultured OI fibroblasts. We also measured the quantity of peptide-bound hydroxyproline excreted in the urine and found evidence of normal collagen turnover in vivo in OI. The morphology of normal and OI fibroblasts in monolayer was also examined and a consistent abnormality of OI cells was discovered.

\section{PATIENTS}

Eleven subjects with osteogenesis imperfecta were examined. Their ages varied between 1 and 50 years. Clear evidence of autosomal dominant inheritance was apparent in 8 of these subjects; the remaining 3 were assumed to be new mutations. All had a history of multiple fractures; the clinical phenotypes conformed with the tarda type in all cases but one, coded patient $O I$ in the tables. The latter died from multiple fractures in early infancy; and resembled the congenita phenotype. Blue sclera were present in all subjects.

\section{METHODS}

Human fibroblast cell cultures were established from punch skin biopsies of age-matched normal control subjects and patients with osteogenesis imperfecta. The site of biopsy was usually the deltoid region although some of the control cultures were from foreskin. The explants were serially propagated, using the techniques of Hayflick (9), and grown in a medium containing Eagle's minimal essential medium (25) supplemented with sodium bicarbonate $(2.2 \mathrm{~g} /$ liter $)$, sodium pyruvate solution (10 ml/liter) (26), Eagle's antibiotic preparation (10 ml/liter), 6\% newborn calf serum (27). The cell cultures were periodically examined by several methods for the presence of mycoplasma; no infection occurred in the course of our investigation. All explants were harvested with Versene-trypsin solution and subcultured at matched generation time into Falcon disposable flasks or petri dishes.

Cell cultures were inoculated with $2.5 \mu \mathrm{Ci}$ isotopicallylabeled substrate using a 20- $\mu$ l Eppendorf syringe with disposable plastic tips.

Collagen was extracted from fibroblasts by the method of Fitch et al. (6). In this method, noncollagenous proteins are precipitated by heating the sample with $5 \%$ TCA for $1 \mathrm{hr}$ at $90^{\circ}$. The medium is dialyzed for $24 \mathrm{hr}$ against water before extraction, thus removing small peptides and any isotope which has not been incorporated.

DNA was determined as deoxyribose using the method of Burton (3) as modified by Tedesco and Mellman (23). The DNA is denatured by heating with perchloric acid and the deoxyribose thus liberated is coupled with diphenylamine; the resulting colored complex is read photometrically at $600 \mathrm{~nm}$.

Radioactively-labeled hydroxyproline in collagen was determined by the method of Juva and Prockop (10); an internal standard was added to calculate recovery. The recoveries in our study $(35-45 \%)$ are in the range reported by the original authors $(35-49 \%)$.

Most samples were flash-evaporated before counting and the radioactivity counted in a Unilux II liquid scintillation counter (28) using Aquasol as the scintillator.

Serial extraction of collagen from fibroblasts was performed as follows: cells were incubated with ${ }^{14} \mathrm{C}$-labeled substrate for periods of $24,48,72$, or $96 \mathrm{hr}$. They were then harvested. Their growth medium was dialyzed overnight and then extracted with hot TCA. The cells were sonicated in normal saline, centrifuged, and the supernatant was extracted with hot
TCA. The counts found in the supernatant medium and in the cell pellet were combined and called "salt-soluble collagen." The pellet from the sonicated cells was extracted for $48 \mathrm{hr}$ at $4^{\circ}$ with $0.2 \mathrm{M}$ citric acid and then centrifuged. The supernatant of this fraction is referred to as "acid-soluble collagen." The final pellet is referred to as "insoluble collagen."

Ion exchange chromatography was performed on the medium in which labeled cells had been grown by a modification of the method of Piez et al. (17). Collagen is denatured by holding the medium at $40^{\circ}$ for $15 \mathrm{~min}$ and then fractionating on CM-Sephadex which has been equilibrated with $0.06 \mathrm{M}$ acetate buffer. After a wash with the starting buffer, the bound material is eluted with $\mathrm{NaCl}(0.4 \mathrm{M})$ in the same buffer. Fractions are collected, extracted with hot TCA, and counted.

Morphologic studies on cultured fibroblasts were performed on paired cultures of OI and normal fibroblasts grown in plastic containers. A Nikon-contrast microscope unit was used at a magnification of 100 times to obtain photomicrographs.

Determinations of total hydroxyproline in urine were performed on aliquots of 24-hr urine collections after prior hydrolysis for $24 \mathrm{hr}$ at $110^{\circ}$ by the method of Kivirikko et al. (11). This method converts hydroxyproline to pyrrole by oxidation and alkaline decarboxylation; the pyrrole is then extracted into toluene, coupled with Erlich's reagent, and the resulting complex is measured colorimetrically. No attempt was made to control diet during the urine collections, which were restricted to periods free of fractures.

All chemicals were reagent grade from Fisher Labs or Schwartz/Mann Chemical Corp. (29). Isotopically labeled material was obtained from New England Nuclear (30) with the following specific activities: L- $\left[{ }^{14} \mathrm{C}\right]$ proline, $4 \mathrm{nmol} / \mathrm{mCi}$; $\mathrm{L}-\left[{ }^{14} \mathrm{C}\right]$ lysine, $32 \mathrm{nmol} / \mathrm{mCi}$; $\left[2-{ }^{14} \mathrm{C}\right]$ glycine, $4 \mathrm{nmol} / \mathrm{mCi}$; $\left[{ }^{14} \mathrm{C}\right]$ galactose, $160 \mathrm{nmol} / \mathrm{mCi}$; and $\left[{ }^{14} \mathrm{C}\right]$ glucose, 200 $\mathrm{nmol} / \mathrm{mCi}$.

\section{RESULTS}

\section{TOTAL URINARY HYDROXYPROLINE IN OI}

Peptide-bound hydroxyproline comprises the major fraction of total hydroxyproline in human urine at all ages $(22,24)$.

Free hydroxyproline excretion is not elevated in OI in our experience, and because total hydroxyproline excretion is within normal range (Fig. 1), we can assume that the peptide-bound fraction is not abnormal in OI. Multiple determinations on the same individual reveal intraindividual variation in hydroxyproline excretion, but this variation is again within normal limits. The age-adjusted reference data for normal subjects are those reported by Smiley and Ziff (21) and Zorab et al. (24). These values are indicated $\pm 2 \mathrm{SD}$ on the graph, except during adolescence where -2 SD is meaningless because of the exceptionally wide variation at this age. Numerous data in our laboratory on non-OI subjects conform with the range of normal values depicted in Figure 1.

It appears, therefore, that total hydroxyproline excretion per $24 \mathrm{hr}$, when corrected for age, is not increased in OI patients when viewed as a group; this finding conflicts with the previous reports by Langness and Bencke $(13,14)$, who found high excretion for the group. On the other hand, hydroxyproline excretion can be very low in some of our patients as reported by Riley et al. (20).

\section{PROLINE INCORPORATION AND HYDROXYLATION}

Incorporation into collagen of isotope from uniformly labeled $\mathrm{L}-\left[{ }^{14} \mathrm{C}\right]$ proline is not abnormal in OI cells when compared with control cells. This observation holds in either the log or the stationary phase of cell growth.

Hydroxylation of proline is also normal in OI cells under 


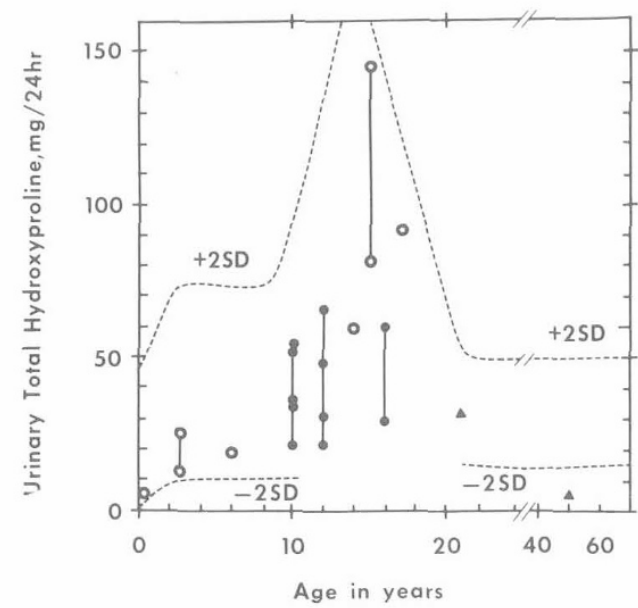

Fig. 1. Total (free and peptide bound) urinary hydroxyproline sretion in osteogenesis imperfecta $(O I)$. Multiple determination on same individual are joined by - Unrelated subjects are resented by $\circ$. $\bullet$ : Three affected sibs; $\mathbf{\Delta}$ : affected parent-child. The lits of $2 \mathrm{SD}$ are indicated ---.

her $\log$ or stationary growth conditions (Fig. 2). When ltures were supplemented with ascorbic acid $(50 \mu \mathrm{g} / \mathrm{ml})$, OI d normal cells responded comparably. Recovery experients after labeling fibroblast collagen with $\left[{ }^{14} \mathrm{C}\right]$ proline veal that $90 \%$ or more of the incorporated isotope is found the proline and hydroxyproline residues.

Incorporation of uniformly labeled L- $\left[{ }^{14} \mathrm{C}\right]$ lysine into OI roblasts is normal and in this respect mimics the findings for proline.

\section{INCORPORATION OF GALACTOSE AND GLUCOSE}

Incorporation of $\mathrm{L}-\left[{ }^{14} \mathrm{C}\right]$ galactose into hot TCA-extractle material is normal in OI (Table 1). By comparison with actose very few counts are incorporated from glucose; again ere was no difference between OI cells and normal roblasts.

\section{EXTRACTABILITY OF COLLAGEN}

The pattern of collagen extraction with salt and $0.2 \mathrm{M}$ citric id is normal in OI, when the cells are labeled with uniformly reled $\left[\mathrm{L}-^{14} \mathrm{C}\right]$ proline (Table 2 ). Incubation in the presence label for 48 or $96 \mathrm{hr}$ did not alter the extraction pattern. e strain from patient $R F$ was the only line which nsistently gave erratic results compared with those of other or normal cell strains. Because it alone showed a more luble form of collage on the average, this finding is nsidered as a trait typic. 1 of the cell line rather than a neral chemical defect in OI.

\section{ION EXCHANGE CHROMATOGRAPHY}

After ion exchange chromatography on CM-Sephadex, mparable biphasic profiles were obtained from the medium eled with $\left[{ }^{14} \mathrm{C}\right]$ lysine when OI fibroblasts and matching ntrols were analyzed (Fig. 3). The ratio between the first d second peak heights was approximately $2 / 1$ in both cases. ak 1 contains predominantly $\alpha 1$ chains and its dimers and cursor material; peak 2 contains mainly $\alpha 2$ chains and their zcursors with a small amount of the dimer between $\alpha_{1}$ and (17). The $2 / 1$ ratio corresponds to the known composition normal tropocollagen, which consists of $(\alpha 1)_{2} \alpha 2$. The propriate ratio and elution pattern was obtained with three ferent control cell lines, and with cells from two different probands (from patients $R F$ and $O I$ ). When $\left[2-{ }^{14} \mathrm{C}\right]$ glycine was used as the label the results were similar in four additional control cell lines and three other OI strains.

\section{CELL MORPHOLOGY}

Fibroblasts in both $\log$ and stationary phases of growth show a morphologic abnormality which distinguishes OI cells from normal cells (Figs. 4 and 5). Normal cells in log phase have an elongated spindle shape, whereas OI cells at the same stage of growth in log phase are tessellated and irregular in shape. The difference between OI and normal cells is exaggerated in the stationary phase of culture. The shape of normal fibroblasts allows them to intercalate with each other in a regular or "smooth" pattern. On the other hand, the OI fibroblasts, because of their irregular shapes, present a "rough" appearance. It should be noted that OI cells require a longer time to achieve stationary phase than normal cells seeded at the same density. This difference in growth rate was taken into consideration in the foregoing observations.

We have now examined OI cultures from 11 different probands; each exhibits a smiliar "rough" appearance. Family members with OI also have the same pattern. Disease controls were studied in skin fibroblasts obtained from patients with Sandhoff's disease, Marotaux-Lamy syndrome, type II mucolipidosis, and cystic fibrosis; none exhibits the "rough" growth pattern.

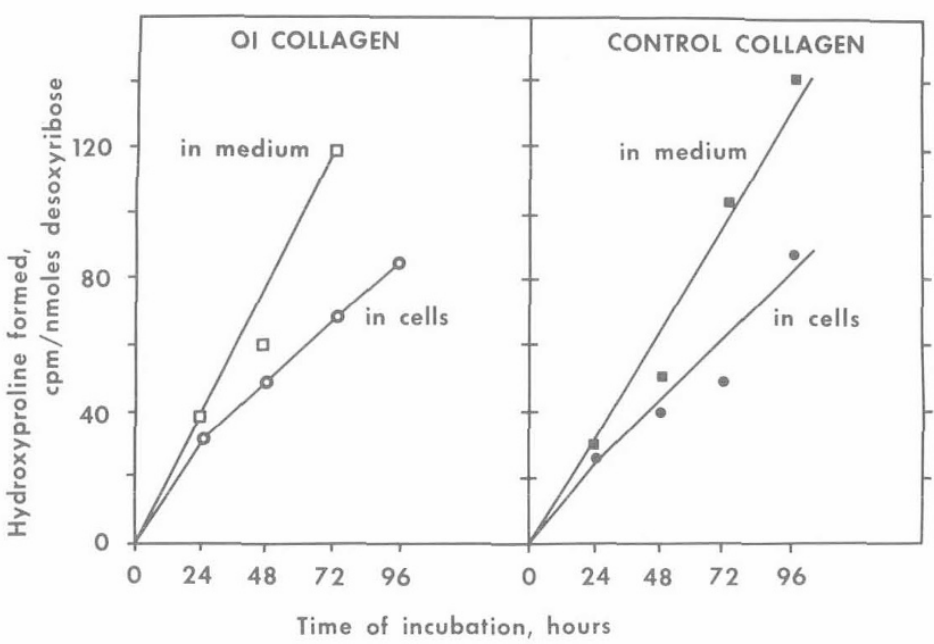

Fig. 2. Hydroxylation of proline in peptide linkage by cultured skin fibroblast from OI and normal subjects. Cells were incubated with 2.5 $\mu \mathrm{Ci}$ of $\left[{ }^{14} \mathrm{C}\right]$ proline for varying time periods. The cells were harvested, the collagen hydrolyzed, and radioactive hydroxyproline determined by the method of Juva and Prockop (10). The OI data are the means of three unrelated tarda patients and one congenita patient. There were no differences between the two types of OI.

Table 1. Incorporation of galactose into fibroblast collagen ${ }^{1}$

\begin{tabular}{lcc}
\hline & \multicolumn{2}{c}{ Galactose, $\mathrm{cpm} / \mathrm{nmole}$ deoxyribose } \\
\cline { 2 - 3 } Cell line & In cells & In medium \\
\hline Controls & & \\
$\quad 3$ lines $(\mathrm{n}=11)$ & $628 \pm 454$ & $569 \pm 428$ \\
OI cell lines & & \\
Patient $D C(\mathrm{n}=3)$ & $693 \pm 318^{2}$ & $491 \pm 278^{2}$ \\
Patient $O I(n=3)$ & $727 \pm 88^{2}$ & $538 \pm 153^{2}$ \\
Patient $R F(\mathrm{n}=?)$ & $610 \pm 204^{2}$ & $547 \pm 262^{2}$ \\
\end{tabular}

${ }^{1}$ Cells were labeled with $2.5 \mu \mathrm{Ci}$ of $\left[1-{ }^{14} \mathrm{C}\right]$ galactose and incubated with the isotope for 7 days. Collagen was extracted as described in the text.

${ }^{2}$ Not significantly different from normal at the 0.05 level. 
Table 2. Extractability of hot TCA-soluble collagen (percentage) ${ }^{1}$

\begin{tabular}{cccc}
\hline \multicolumn{1}{c}{ Cell line } & $\begin{array}{c}\text { Salt-soluble } \\
(\text { mean } \pm 1 \mathrm{SD})\end{array}$ & $\begin{array}{c}\text { Acid-soluble } \\
(\text { mean } \pm 1 \mathrm{SD})\end{array}$ & $\begin{array}{c}\text { Insoluble } \\
(\text { mean } \pm 1 \mathrm{SD})\end{array}$ \\
\hline $\begin{array}{c}\text { Controls } \\
\quad \text { lines }(\mathrm{n}=13)\end{array}$ & $79.7 \pm 5.8$ & $8.2 \pm 3.5$ & $12.1 \pm 5.3$ \\
$\begin{array}{c}\text { OI cell lines } \\
\text { Patient } D C \\
\quad(n=4)\end{array}$ & $79.5 \pm 4.4^{2}$ & $8.0 \pm 5.3^{2}$ & $12.5 \pm 3.9^{2}$ \\
$\begin{array}{c}\text { Patient } \text { OI } \\
(\mathrm{n}=8)\end{array}$ & $79.5 \pm 4.3^{2}$ & $9.2 \pm 3.7^{2}$ & $11.6 \pm 3.7^{2}$ \\
$\begin{array}{c}\text { Patient } R F \\
(\mathrm{n}=6)\end{array}$ & $85.0 \pm 12.6^{2}$ & $5.8 \pm 5.0^{2}$ & $9.2 \pm 9.6^{2}$ \\
\hline
\end{tabular}

${ }^{1}$ Details of extraction are outlined in the text. Values for 48-96 hr incubation have been pooled, since analysis of variance shows no significant difference in the extraction pattern at these two periods.

${ }^{2}$ Not significantly different from normal at the 0.05 level.

\section{DISCUSSION}

The characteristic and unusual growth pattern in monolayer culture evinced by fibroblasts derived from OI patients demonstrates that the lesion underlying this disease is expressed in vitro. However, this lesion in itself does not reveal the nature of the underlying abnormality, although it does hold out realistic hopes that the biochemical defect can be identified in cultured fibroblasts. Conversely, the facets of collagen metabolism found to be normal in OI fibroblasts are unlikely to be reversions from an abnormal state in vivo.

Our experimental observations allow us to discard several potential errors of collagen metabolism as possible causes of a biochemical lesion in OI.

The fact that lysine and proline are incorporated at normal rates into OI collagen suggests that the rate of collagen synthesis in vitro is normal in this disease. Furthermore, normal hydroxylation of proline makes it unlikely that the disease is caused by an abnormality of proline hydroxylation in the nascent polypeptide chain. A disease of collagen, caused by a defect in lysine hydroxylation, has already been identified $(12,18)$, and it does not resemble OI. These observations indicate that enzymatic elaboration of collagen probably proceeds normally in OI, as would be expected in a dominantly inherited trait. The normal excretion of peptidebound hydroxyproline into the medium in vitro, and into the urine in vivo indicates that cellular export of OI collagen is also not aberrant. Finally, the normal solubility of collagen derived from OI fibroblasts suggests that abnormal covalent cross-linking of collagen is not a constant feature of this disease, a deduction further supported by the normal urinary excretion rates of peptide-bound hydroxyproline.

The urinary data in our study were controlled for age and we were careful to avoid periods of fracture repair in our studies. Under these conditions we did not discover hyperexcretion of bound hydroxyproline as reported earlier (13), nor did we find hypoexcretion of a consistent nature as noted by Riley and Brown (19). Any further discrepancy between our findings in vitro and those reported by Brown (2) can probably be explained by differences in techniques of cell culture, of labeling collagen, and in the coefficients used to express synthesis rates in normal and OI cells.

The hypothesis that OI is caused by a collagen defect is an attractive one because of the histochemical evidence $(1,4,5)$ and the clinical evidence that OI skin is underendowed with collagen (22). Furthermore, the morphologic evidence in vitro is consistent with the hypothesis of a collagen defect which results in imperfect adherence of the cells one to another.
There is one type of defect not ruled out by our findings: namely, a single amino acid substitution in the collagen chain. In particular, if a charged group were substituted for a neutral charge-bearing amino acid in collagen, the result is likely to be a regional uncoiling of its triple helix for electrostatic and possibly also for steric reasons. One can readily visualize various types of substitution, analogous with the hemoglobinopathies which would be an explanation for the phenotypic heterogeneity in OI such as the enhanced salt solubility of the fibroblast collagen in patient $R F$ and the individual differences of hydroxyproline excretion reported by various observers.

Finally, the hypothesis of a defect in the primary sequence of a triple-strand structural protein such as collagen would account readily for the dominant pattern of inheritance in this disease. Assigning the mutation to the gene which controls the sequence of $\alpha 2$ chains could explain most simply the localization of the OI phenotype to noncartilaginous tissues which synthesize $[\alpha 1(\mathrm{I})]_{2} \alpha 2$ collagen; the collagen of cartilagenous structures has the chain composition $[\alpha 1(\mathrm{II})]_{3}$, where the $\alpha 1$ (II) polypeptide differs from the $\alpha 1$ (I) chain in the content of hydroxylysine-linked carbohydrate and amino acid composition.

\section{SUMMARY}

Excretion of peptide-bound hydroxyproline in urine is within normal limits in patients with dominantly inherited OI. Cultured skin fibroblasts from OI patients exhibit abnormal morphology in monolayer, which suggests that the basic defect in $\mathrm{OI}$ is expressed in vitro. Collagen biosynthesis was therefore examined in cultured fibroblasts derived from OI patients and from controls matched as to age, site of biopsy, phase of growth, and generation number in culture. Normal incorporation and hydroxylation of proline and normal incorporation of lysine and galactose were found in OI cultures. The hot TCA-soluble collagen fraction in OI cells in their growth medium also exhibits normal extractability in salt and acid solutions. These findings suggest that dominantly inherited OI is not caused by an enzymatic defect responsible for hydroxylation, cross-linking, or export of collagen polypeptide chains. When we then examined $\left[{ }^{14} \mathrm{C}\right]$ lysine-labeled collagen

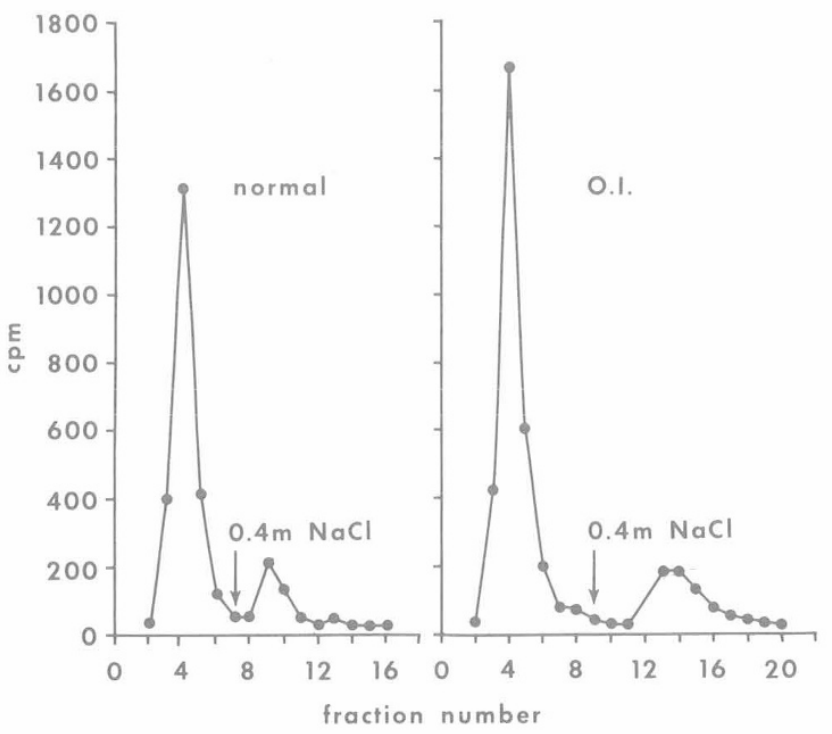

Fig. 3. Fractionation of salt-soluble collagen on carboxymethyl Sephadex C-25. The cells were incubated with $2.5 \mu \mathrm{Ci}\left[\mathrm{L}^{-14} \mathrm{C}\right]$ lysine for 1 week. The medium was then dialyzed, denatured by heating at $40^{\circ}$ for $15 \mathrm{~min}$, and then fractionated on a column $(30$ by $1.5 \mathrm{~cm})$ at $40^{\circ}$. The fractions were then extracted with hot trichloroacetic acid and an aliquot counted in Aquasol. O.I.: osteogenesis imperfecta. 

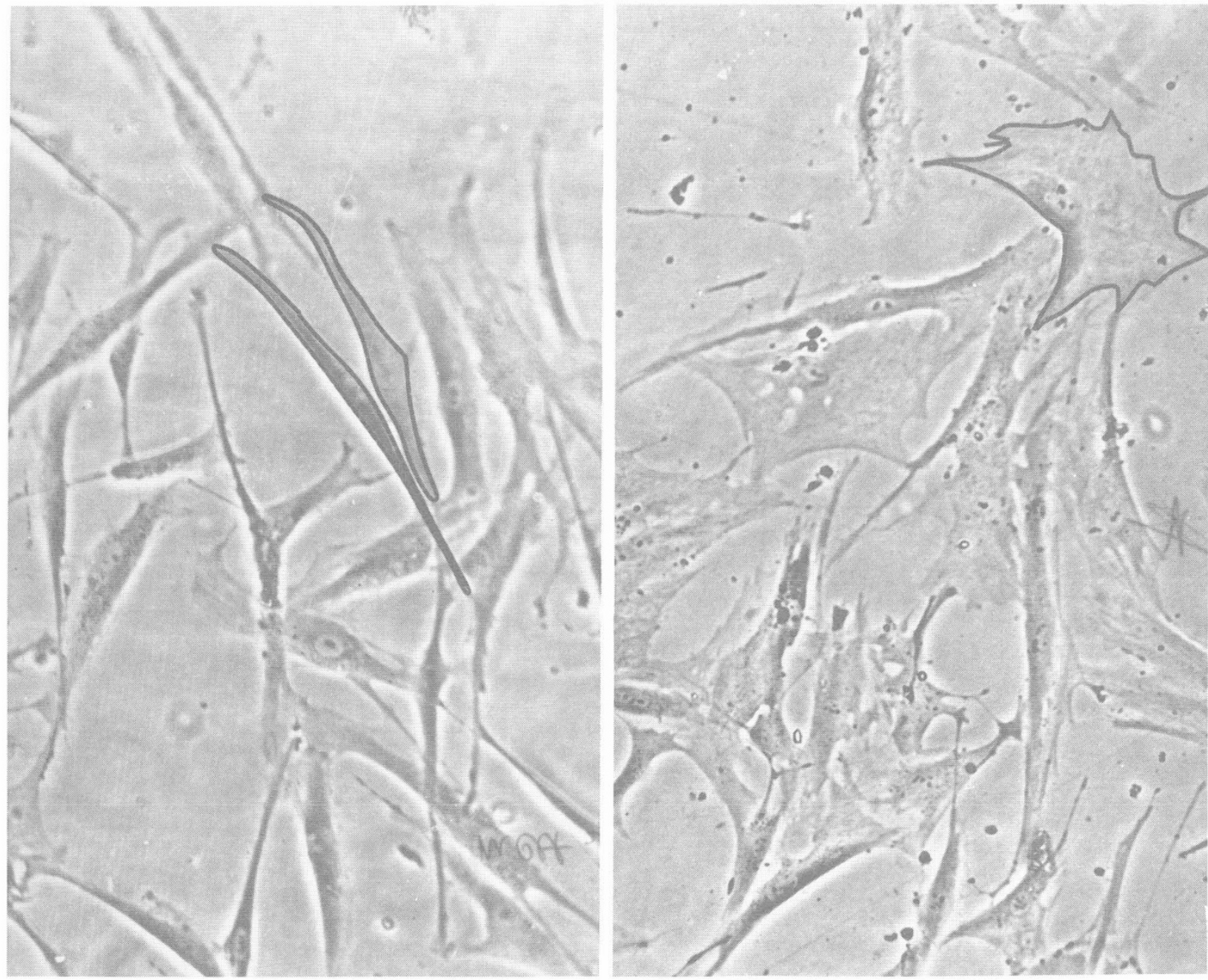

Fig. 4. Cell morphology of osteogenesis imperfecta (OI) in the log phase of growth. The left side shows the spindle-shaped cells characteristic of normal fibroblasts. The dotted outline emphasizes a typical cell. The right side shows a typical OI cell. The irregular appearance of OI cells is readily apparent. Photos were taken on a phase contrast microscope. Magnification, $X 100$.

by ion exchange chromatography, we found a normal ratio of $\alpha 1$ to $\alpha 2$ polypeptide chains in OI cells. The combined evidence points to a defect in the primary sequence of one-half of the collagen chains under the control of a single gene locus as the most likely cause of the dominantly inherited abnormalities which characterize this type of OI.

\section{ADDENDUM IN PROOF}

A recent report (Francis, M. J. O., Smith, R., and Pauze, R. J.: Instability of polymeric skin collagen in osteogenesis imperfecta. BMJ, $i$ : 421-424 (1974)) describes normal stability, with reduced total amount of whole skin polymeric collagen in "blue-eyed" OI. These findings extend the observations of Stevenson et al. on whole skin (22) and confirm our own on cultured skin fibroblasts from similar OI patients. In patients with the more severe "white-eyed" form of OI, Francis and coworkers observed lowered resistance to depolymerization of whole skin collagen.

\section{REFERENCES AND NOTES}

1. Blumcke, S, and Niedorf, H. R.: Histochemical and fine structural studies on the cornea with osteogenesis imperfecta congenital. Virchow's Arch. Abt. B Zellpathol., 11: 124 (1972).

2. Brown, D. M.: Collagen metabolism in f.: roblasts from patients with osteogenesis imperfecta. In: B. Frame, A. M. Parfitt, and H. Duncan: Clinical Aspects of Metabolic Bone Disease, pp. 303-307 (Excerpta Medica, Amsterdam, 1973).
3. Burton, K.: A study of the conditions and mechanisms of the diphenylamine reaction for the calorimetric determination of deoxyribonucleic acid. Biochem. J., 62: 315 (1956).

4. Eichholtz, W., and Muller, D.: Elektronenmukroskopische Befunde an der Hornhaut und Sklera bei Osteogenesis imperfecta. Klin. Monatsbl. Augenheilk, 161: 646 (1974).

5. Falvo, F., and Bullough, P. G.: Osteogenesis imperfecta: A histochemical analysis. J. Bone Joint Surg., 55-A: 275 (1973),

6. Fitch, S. M., Harkness, M. L, R, and Harkness, R. D.: Extraction of collagen from tissues. Nature, 176: 163 (1955).

7. Freda, V. J., Vosburgh, G. J., and DiLiberti, B.: Osteogenesis imperfecta congenita, presentation of 16 cases and review of the literature, Obstet, Gynecol,, 18: 535 (1961).

8. Furness, E. T., and White, T. A.: A case of osteogenesis imperfecta diagnosed in utero. Med. J. Aust., 1: 390 (1973).

9. Hayflick, L.: The limited in vitro lifetime of human diploid cell strains. Exp. Cell Res., 37: 614 (1965).

10. Juva, K., and Prockop, D. J.: Modified procedure for the assay of ${ }^{3} \mathrm{H}$ or ${ }^{14} \mathrm{C}$-labeled hydroxyproline. Anal. Biochem., 15: 77 (1966).

11. Kivirikko, K. I., Laitinen, O., and Prockop, D. J.: Modifications of a specific assay for hydroxyproline in urine. Anal. Biochem., 19: 249 (1967).

12. Krane, S. M., Pinnell, S. R., and Erbe, R. W.: Lysyl-protocollagen hydroxylase deficiency in fibroblasts from siblings with hydroxylysine-deficient collagen. Proc. Nat. Acad. Sci. U.S.A., 69: 2899 (1972).

13. Langness, U., and Behnke, H.: Biochemische Untersuchungen Zur Osteogenesis imperfecta. Deut. Med. Wochenschr., 95: 213 (1970).

14. Langness, U., and Behnke, H.: Collagen metabolites in plasma and urine in osteogenesis imperfecta. Metabolism, 20: 456 (1971).

15. McKusick, V. A.: Heritable Disorders of Connective Tissue, Ed. 3 

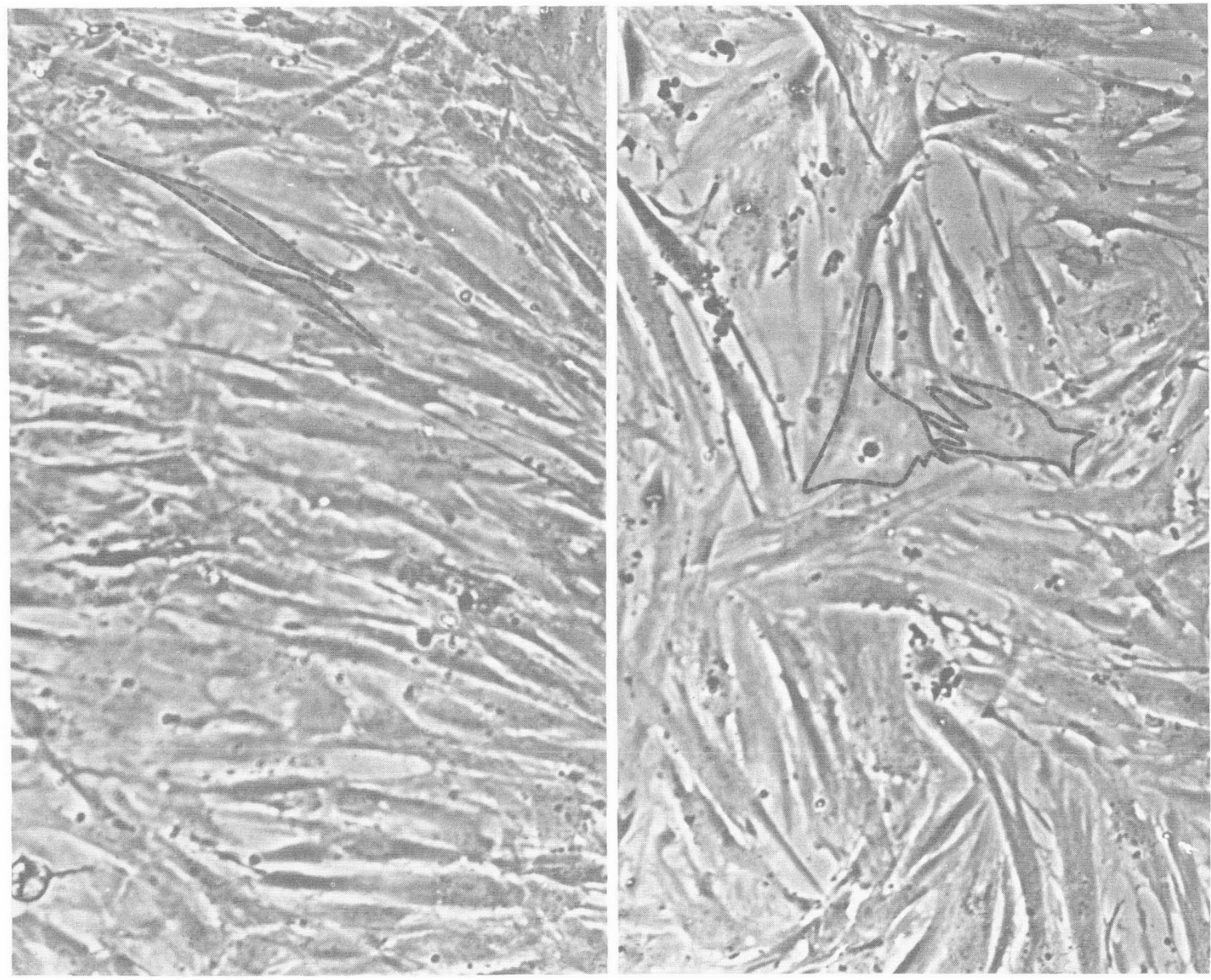

Fig. 5. Cell morphology of osteogenesis imperfecta (OI) and normal fibroblasts at stage of confluency. The left side shows the normal smooth pattern of intercalated fibroblasts. The right side shows the "rough" pattern exhibited by OI fibroblasts. The cell morphology is irregular and does not permit close packing. The dotted outline marks off typical cells. Photos were taken on a phase contrast microscope. Magnification, $X 100$.

(C. V. Mosby Co., St. Louis, 1966).

16. McKusick, V. A.: Mendelian inheritance in man, Ed. 3 (Johns Hopkins Press, Baltimore, 1971).

17. Piez, K. A., Eigner, E. A., and Lewis, M. S.: The chromatographic separation and amino composition of the subunits of several collagens. Biochemistry, 2: 58 (1963).

18. Pinnell, S. R., Krane, S. M., Kenzora, J. E., and Glimcher, M. J.: A heritable disorder of connective tissue. New Engl. J. Med., 286: 1013 (1972).

19. Riley, F. C., and Brown, D. M.: Morphologic and biochemical studies in osteogenesis imperfecta. J. Lab. Clin. Med., 78: 1000 (1971).

20. Riley, F. C., Jowsey, J., and Brown, D. M.: Osteogenesis imperfecta: Morphologic and biochemical studies of connective tissue. Pediat, Res., 7: 757 (1973).

21. Smiley, J. D., and Ziff, M.: Urinary hydroxyproline excretion and growth. Physiol. Rev., 44: 30 (1964).

22. Stevenson, C. J., Bottoms, E,, and Shuster, S.: Skin collager osteogenesis imperfecta. Lancet, $i: 860$ (1970).

23. Tedesco, J. A., and Mellman, W. J.: Desoxyribonucleic acid assay as a measure of cell number in preparations from monolayer cell cultures and blood leucocytes. Exp. Cell Res., 45: 230 (1967).

24. Zorab, P. A., Clark, S. Hamson, A., and Seel, J. R.: Hydroxyproline excretion and height velocity in adolescent boys. Arch. Dis. Childhood, 45: 763-765 (1970).

25. Lancaster, G., Gold, R., Goldman, H., Scriver, C., and Wong, I.: Properties of cultured skin fibroblasts and their collagen osteogenesis imperfecta. Amer. J. Hum. Genet., 25: 44A (1973).

26. Grand Island Biological Company, Chagrin Falls, Ohio.

27. Flow Laboratories, Rockville, Md.

28. Nuclear-Chicago, Corp., Des Plaines, Illinois.

29. Philadelphia, Penn. and Orangeburg, N.Y.

30. Boston, Mass.

31. The authors wish to thank Cheryl Rockman for her help in the early stages of our work, Dr. Francis H. Glorieux at the Montreal Shriners Hospital for cooperation in obtaining some of the urine collections, and Mrs. Huguette Ishmael and Miss Lynne Prevost for typing the manuscript.

32. This work was supported by grants to the Medical Genetics Group by the Medical Research Council of Canada and from the Quebec Network of Genetic Medícine. Support from the National Genetics Foundation (New York) during the early stages is also acknowledged. Dr. Gold was a beneficiary of the National Genetics Foundation Fellowship program until September 1973.

33. Informed consent was obtained for the biopsy material from parents or subjects when they were consenting adults. Patients were aware that the material was to be used for research purposes only.

34. This research was presented in part at the 25th Annual Meeting of the American Society of Human Genetics, Atlanta, 1973 (25).

35. Requests for reprints should be addressed to: G. Lancaster, Ph.D. McGill University-Montreal Children's Hospital Research Institute, 2300 Tupper St., Montreal H3H 1P3, Quebec, Canada.

36. Accepted for publication September 6, 1974 . 